\title{
Antimicrobial Effects of Several Essential Oil from Aromatic Plants
}

\author{
Felicia TUȚULESCU ${ }^{1 *}$, Maria DINU ${ }^{1}$, Alexandru Radu CORBU ${ }^{1}$, \\ Elena Iuliana IONIȚ $\breve{A}^{2}$
}

\author{
${ }^{1}$ University of Craiova, Faculty of Horticulture, Department of Horticulture and Food Science, 13 A.I. Cuza Street, 200585 Craiova, Romania; \\ felixdragomir@yahoo.com ("correspondingauthor);dinumariana@hotmail.com;corbu_lx@yahoo.co.uk \\ ${ }^{2}$ University of Medicine and Pharmacy "Carol Davila", 8 Eroii Sanitari Street, 050474 București, Romania; ionita_elena_iuliana@yahoo.com
}

\begin{abstract}
Essential oils (EOs) have been long recognized for their antibacterial, antifungal, antiviral, insecticidal and antioxidant properties. The present research aimed to study the antimicrobial effects of some volatile oils from aromatic plants (sweet basil and dill) against several microorganisms, namely Bacillus subtilis, Alternaria alternata and Penicillium expansum. The oils have been extracted through distillation procedures and the antimicrobial action of the oils was assessed through the disc diffusion method. The best effect against the Bacillus subtilis strain has occurred when the essential oil of dill was undiluted. Regarding the the Alternaria species, it was noted that dill volatile oil has acted in an efficient way only undiluted. As the oil's concentration decreased, the strain becomed resistant. The sweet basil oil has proven to be highly effective when acting against the Bacillus strain. By volatilization, the sweet basil oil produced a strong antimicrobial effect, even in control disc, in which it was noticed a small development of colonies comparing with the dill oil. The results indicated that the sweet basil essential oil exerted an antimicrobial effect both against the tested bacteria and moulds, while the dill oil had a great inhibitory action on Bacillus subtilis and Alternaria alternata, but was less efficient against Penicillium expansum.
\end{abstract}

Keywords: sweet basil, dill, volatile oil, bacteria, moulds

\section{Introduction}

The essential oils (also called volatile oils) are obtained by hydrodistillation of whole tissues or seeds of common culinary herbs, spices and aromatic plants (Jiao et al., 2012; Jila et al., 2012; Solorzano Santos et al., 2012; Luu et al., 2013; Sandrine et al., 2013; Sibel et al., 2014; Tongnuanchan et al., 2014). The volatile oils contain bioactive phytochemicals and may represent natural alternatives to synthetic chemicals used in food preservation (Delaquis et al., 2002). In recent years, a large number of essential oils and their constituents have been investigated for their antimicrobial properties against some bacteria and fungi (Kalemba and Kunicka, 2003).

The influence of essential oils extracted from different aromatic plants on microorganisms has been performed by many authors. Bagamboula et al. (2001) studied the effect of basil oil upon two species of Shigella found in foods. Burt (2004) analyzed several plant essential oils from setting their antimicrobial effect and the possibility of their use in food preservation. Carmo et al. (2008) studied the effect of oregano essential oil on several Aspergillus species isolated from foods. Chao et al. (2000) investigated the inhibitory effects of 45 oils on 4 Gram positive bacteria and 4 Gram negative bacteria, 2 moulds and one yeast. Daferera et al. (2003) tested the effectiveness of seven essential oils (oregano, thyme, dictamnus, marjoram, lavender, rosemary, sage and pennyroyal) on two species of moulds (Botrytis cinerea, Fusarium solani var. coeruleum) and one bacteria (Clavibacter michiganensis subsp. michiganensis) with phytopatogen rol. Helander et al. (1998) investigated the effect of essential oils compounds (carvacrol, (+)- carvone, thymol, transcinnamaldehyde) on two species of the Enterobacteriaceae family (Escherichia coli $\mathrm{O}_{157}: \mathrm{H}_{7}$ and Salmonella typhimurium). Lambert et al. (2001) studied the effect of oregano essential oil with carvacrol and thymol on Staphylococcus aureus and Pseudomonas aeruginosa and noted that certain combination of carvacrol-thymol increased the inhibitory effect of oil of oregano. Lv et al. (2011) tested on Escherichia coli, Staphylococcus aureus, Bacillus subtilis and Saccharomyces cerevisiae essential oil of basil, oregano, bergamot and perilla using agar disk diffusion and broth dilution methods. Analyzing the essential oils by GC/MS, they found that phenols and terpenes were the major antimicrobial compounds in oregano and basil essential oil. The dominant active components of bergamot essential oil were alcohols, esters and terpenes. For perilla essential oil, the major active 
478

constituents were mainly ketones. Savory, laurel, oregano, basil, cumin, seafennel, myrtle, pickling herb and mint essential oils, combined or single, were tested on several species of microorganisms (Salmonella typhimurium, Bacillus cereus, Staphylococcus aureus, Enterococcus faecalis, Escherichia coli, Yersinia enterocolitica, Saccharomyces cerevisiae, Candida rugosa, Rhizopus oryzae and Aspergillus niger ) by Özcan and Erkmen (2001). Rauha et al. (2000) investigated 13 phenolic substances and 29 extracts prepared from Finnish plant materials. The microorganisms used in their study were Aspergillus niger, Bacillus subtilis, Candida albicans, Escherichia coli, Micrococcus luteus, Pseudomonas aeruginosa, Saccharomyces cerevisiae, Staphylococcus aureus and Staphylococcus epidermidis. They found that flavone, quercetin and naringenin were effective in inhibiting the growth of the organisms.

The classical methods commonly used to assessed essential oils antibacterial and antifungal activities are the agar diffusion method (paper disc as well) and the dilution method (agar and liquid both), as well as turbidimetric and impedimetric monitoring of microorganism growth in the presence of tested essential oils (Kalemba and Kunicka, 2003).

Many authors have studied the effect of dill extracts and dill oil on microorganisms. Jirovetz et al. (2003) reported a high activity of the essential $A$. graveolens oil against the mold Aspergillus niger and the yeasts Saccharomyces cerevisiae and Candida albicans. In antifungal investigations, Singh et al. (2006) found that the dill essential oil was highly effective for controlling the growth of Penicillium citrinum and Aspergillus niger. In antibacterial investigations, the dill acetone extract has shown better activity against Staphylococcus aureus and Bacillus cereus in comparison with a commercial bactericide, while the dill essential oil has shown better activity against Pseudomonas aeruginosa.

Common basil (Ocimum basilicum L.) has been extensively utilized in foods as a flavouring agent, in perfumery and medical industries (Telci et al., 2006).

The present study aimed to investigate the antimicrobial effects of some oils extracted from sweet basil and dill against Bacillus subtilis, Alternaria alternata and Penicillium expansum using the disc diffusion method. The main objective of the study was to establish the inhibitory capacity of the two studied essential oils so they can be successfully used for the preservation of food.

\section{Materials and Methods}

\section{Plant material}

Dill (Anethum graveolens L.) and basil (Ocimum basilicum) were provided by Banu Maracine Didactical Station of University of Craiova $\left(44^{\circ} 20^{\prime} 0^{\prime \prime} \mathrm{N}, 23^{\circ} 49^{\prime} 0^{\prime \prime} \mathrm{E}\right)$ located in Oltenia region of Romania. Plants used in this experiment have not been treated with plant protection products. The amount of essential oil was $2 \mathrm{ml}$ resulted from one kilogram of dill plants, whereas for basil the sample consisted of $5 \mathrm{ml}$ from $2.5 \mathrm{~kg}$ of plants.

In order to extract the dill volatile oil, young stalks and leaves have been used, while for the sweet basil volatile oil, plants which had reached to their full maturity have been chosen, including stalks, leaves and inflorescences.

\section{The essential oil extract}

The essential oils were extracted through hydrodistillation (Gîrd, 2009) using a NeoClevenger device. Flask extraction device was adapted to be inserted of 50-100 g shredded vegetable and 500-1,000 mL solvent (usually water). The mixture thus formed was subjected to direct flame heating, sieve. When the solvent reached the boiling point of the extraction, the essential oil was distilled and captured in the graduated tube of the apparatus. After being obtained, the oils were preserved within hermetically closed recipients, under refrigeration.

\section{The antimicrobial activity of the extract}

The tests regarding the antimicrobial activity have been performed against two mould strains belonging to the species Alternaria alternata and Penicillium expansum, as well as against a $G(+)$ sporulated bacteria, namely Bacillus subtilis. The antimicrobial action of the oils was assessed by the disc diffusion method as described by Hussain et al. (2008). The filter discs $(6 \mathrm{~mm}$ in diameter) were individually soaked with $15 \mu \mathrm{L}$ of essential oils and placed on the agar plates which were previously inoculated with the tested microorganisms. Both undiluted oils, as well as oils diluted with $n$-hexane (at 1:1, respectively at $2: 1$ ratio), were compared with the control (a disc imbibed with n-hexane only, which brought no antimicrobial effect at all). The Petri dishes were kept at $4{ }^{\circ} \mathrm{C}$ for $2 \mathrm{~h}$. The plates were incubated at $37^{\circ} \mathrm{C}$ for $24 \mathrm{~h}$ for bacteria and at $30^{\circ} \mathrm{C}$ for $48 \mathrm{~h}$ for fungal strains.

\section{Statistical data}

Antimicrobial activity was evaluated by measuring the diameter of the growth inhibition zones in millimetres (including disc diameter of $6 \mathrm{~mm}$ ) for the test organisms and comparing to the control. A zone of "no growth" around the disk defined the extent of antimicrobial activity. The measurements of inhibition zones were carried for three sample replications, and values were calculated as the average of three replicates.

\section{Results and Discussion}

The influence of dill oil against the Bacillus subtilis strain

The best effect against the Bacillus subtilis strain has occurred when the essential oil of dill was undiluted. As the oil's concentration decreased, the Bacillus colonies increased, which indicated that the strain were resistant at diluted oil. After a thermostatical conditioning of 7 days, it was found that for the cases of undiluted oil and for 1:1 dilution, the inhibition zone remained clean, while at the 2:1 dilution the colonies grew up on a very wide area (Table 1, Figs. 1 and 2).

When the mould from the Alternaria species was tested, it was noted that dill volatile oil has acted in an efficient way only undiluted. As the oil's concentration decreased, the strain becomes resistant. The 1:1 dilution with $\mathrm{n}$-hexane determinate a particularly low inhibitory level, while in the case of 2:1 dilution, the colonies grow up even on the disc imbibed with oil. The diameters of the inhibition areas are presented in Table 1 and Figs. 3, 4. 
Table 1. The diameters of the inhibition areas determined by the undiluted and diluted dill oil for the studied species

\begin{tabular}{|c|c|c|c|c|c|}
\hline \multirow[b]{2}{*}{ Species } & \multirow{2}{*}{ Concentration } & Undiluted oil & $1: 1$ & 2:1 & $\mathrm{n}$-hexane \\
\hline & & \multicolumn{4}{|c|}{ Diameters $(\mathrm{cm})$ of the inhibition zones } \\
\hline Bacillus subtillis & & 2.7 & 2.5 & 2.2 & Susceptible \\
\hline Alternaria alternata & & 2.9 & 1.5 & Susceptible & Susceptible \\
\hline Penicillium expansum & & 2.0 & 1.2 & Susceptible & Susceptible \\
\hline
\end{tabular}

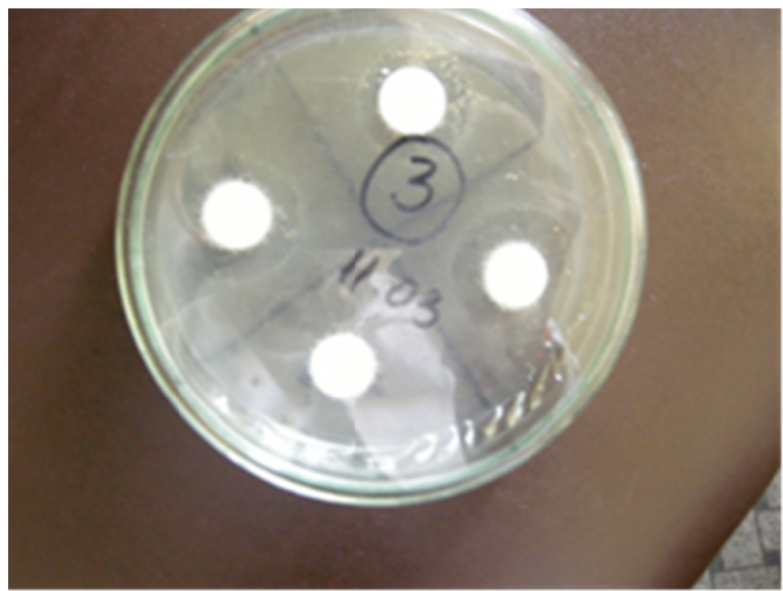

Fig. 1. Diameters of the inhibiting zones at Bacillus subtillis

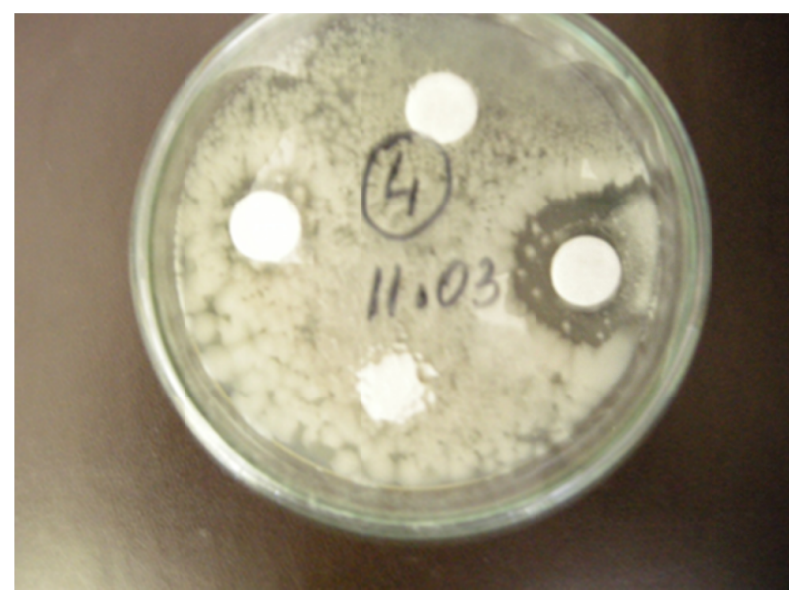

Fig. 3. Diameters of the inhibiting zones at Alternaria alternata

The present results showed that the oil's dilution led to a decrease by half of its inhibitory strength.

In regard to the Penicillium expansum mould, the dill oil had a poor inhibitory action and was effective only when was undiluted.

From the images above it was noted that in the case of the $n$-hexane's presence, the colonies have come to develop even on the disc surface, while in the case of discs imbibed with oil, the colonies were able to develop till near the disc.

Thus, the present findings showed a good inhibitory activity of dill volatile oil against Bacillus species. A hierarchy was established among the tested species using as criterion their susceptibility towards the dill oil's action, as follows: Penicillium expansum $>$ Alternaria alternata $>$ Bacillus subtilis.

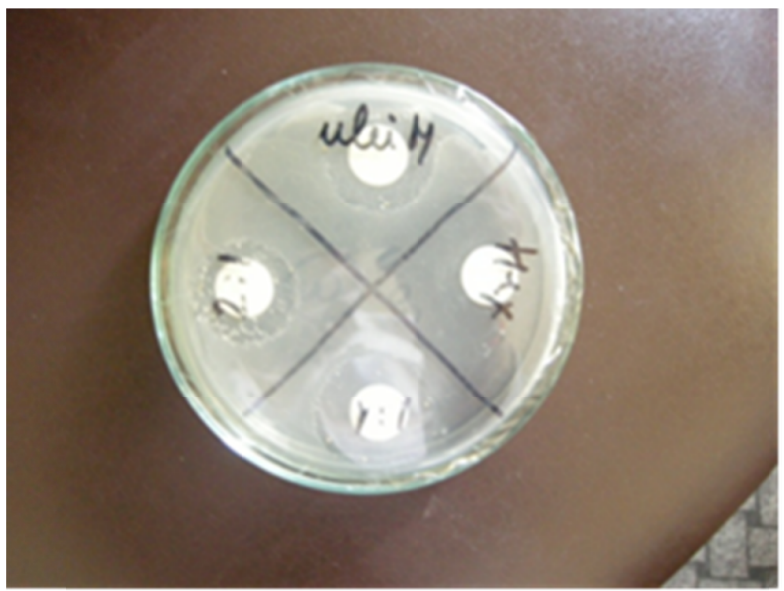

Fig. 2. Diameters of the inhibiting zones at Bacillus subtillis (reverse colonies)

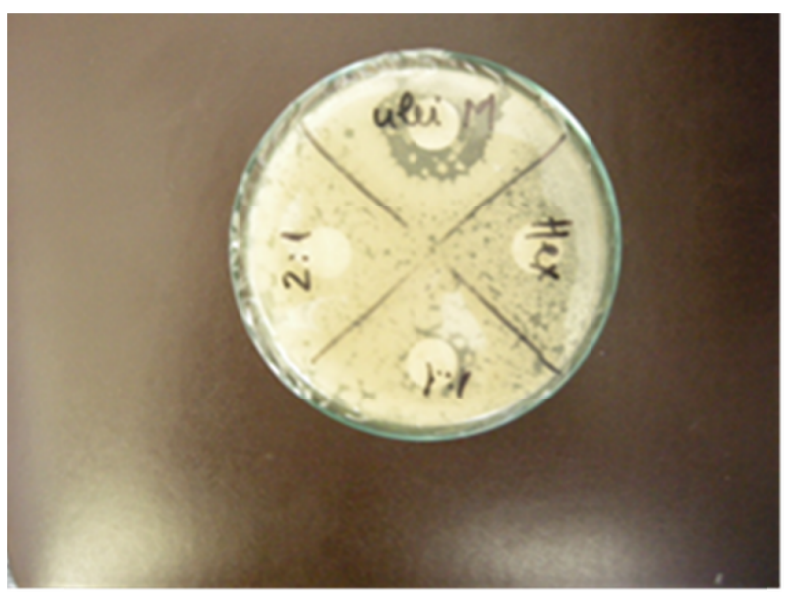

Fig. 4. Diameters of the inhibiting zones at Alternaria alternata (reverse colonies)

The dill (Anethum graveolens $\mathrm{L}$.) contains $2.5 \%-4 \%$ volatile oil within its stalks and young leaves, as well as $1 \%-8 \%$ within its fruits (Burzo, 2015). Nineteen different compounds have been detected within the volatile dill oil (Burzo, 2015). In addition, Delaquis et al. (2002) reported that dill oil consist approximately equal volumes of carvone and D-limonene, which together accounted for $97.5 \%$ of the compounds identified by gas chromatography/mass spectroscopy.

\section{The influence of sweet basil oil}

The sweet basil oil has proven to be highly effective when acting against the Bacillus strain. The effect of this oil against the tested bacterium was microbicidal, because the strain was inhibited from the whole concerned plate' sector where the oil 
Table 2. The diameters of the inhibition areas determined by the undiluted and diluted basil oil for the studied species

\begin{tabular}{|c|c|c|c|c|}
\hline \multirow[t]{2}{*}{ Concentration } & undiluted oil & $1: 1$ & $2: 1$ & n-hexane \\
\hline & \multicolumn{4}{|c|}{ Diameters $(\mathrm{cm})$ of the inhibiting zones } \\
\hline Bacillus subtillis & total susceptible & total susceptible & total susceptible & total susceptible \\
\hline Alternaria alternata & total susceptible & total susceptible & total susceptible & total susceptible \\
\hline Penicillium expansum & total susceptible & 3.5 & 3.0 & susceptible \\
\hline
\end{tabular}

was applied, both when oil was undiluted, as well as when it was diluted with n-hexane at a 1:1 ratio. By volatilization, at the temperature of $25^{\circ} \mathrm{C}$, the sweet basil oil produced a strong antimicrobial effect, even in control disc, in which it was noticed a small development of colonies comparing with the dill oil. The same microbicidal effect was found against the Alternaria alternata strain. The mould of Penicillium species has shown a stronger resistance against the action of the sweet basil oil and in the area where the disc was imbibed with nhexane only, the colonies were resistant. In the case of undiluted oil, the colonies were susceptible, while in cases of the two dilutions, $1: 1$ and 2:1, the area of inhibition decreased as the dilution's ratio increased (Table 2).

Basil essential oils and their principal constituents were found to exhibit antimicrobial activity against a wide range of Gram-negative and Gram-positive bacteria, yeast and mould (Suppakul et al., 2003). In addition, Lv et al. (2011) reported that the essential oil of basil was active against the Grampositive bacteria (Staphylococcus aureus and Bacillus subtilis).

Hussain et al. (2002) assessed the antimicrobial activity of the essential oils obtained from $O$. basilicum against bacterial strains Staphylococcus aureus, Escherichia coli, Bacillus subtilis, Pasteurella multocida and pathogenic fungi Aspergillus niger, Mucor mucedo, Fusarium solani, Botryodiplodia theobromae and Rhizopus solani. They found that the essential oils of $O$. basilicum exhibited strong antimicrobial activity against all the microorganisms tested, but $S$. aureus and $B$. subtilis were the most sensitive microorganisms, while less activity was observed against $M$. mucedo. In addition, the authors noted that $O$. basilicum essential oil showed greater activity against bacterial strains than fungal strains and it possessed stronger antimicrobial activity against Gram-positive bacteria versus Gram-negative bacteria.

The present findings are in accordance with the above mentioned studies and represent adding data to those obtained by many researchers. Further studies will focus on the combined effect of the tested oils and their interaction with certain compounds resulting from food's fermentation (lactic acid, ethyl alcohol, acetic acid).

\section{Conclusions}

The dill oil obtained through distillation procedures had a good antimicrobial effect against Bacillus subtilis species and was more effective against Alternaria alternata species than against Penicillium expansum species. The same hierarchy of inhibition has been confirmed for sweet basil oil, too. The sweet basil oil has proven to be highly effective when acting against the Bacillus strain, its effect being microbicidal.

\section{References}

Bagamboula CF, Uyttendaele M, Debevere J (2001). Inhibitory effect of thyme and basil essential oils, carvacrol, thymol, estragol, linalool and p-cymene towards Shigella sonnei and S. flexneri. Food Microbiology $21: 33-42$.

Burt S (2004). Essential oils: their antibacterial properties and potential application in foods - a review. International Journal of Food Microbiology 94(3):223-253.

Burzo I (2015). Medicinal plants and food composition of spontaneous and cultivated, Ed. Elisavaros Bucharest.

Carmo ES, De Oliveira Lima E, De Souza EL (2008). The potential of Origanum vulgare (Lamiaceae) essential oil in inhibiting the growth of some food-related Aspergillus species. Brazilian Journal of Microbiology 39(2):362-367.

Chao SC, Young DG, Oberg CJ (2000). Screening for inhibitory activity of essential oils on selected bacteria, fungi and viruses. Journal of Essential Oil Research 12(5):639-649.

Daferera DJ, Ziogas BN, Polissiou MG (2003). The effectiveness of plant essential oils on the growth of Botrytis cinerea, Fusarium sp. and Clavibacter michiganensis subsp. michiganensis. Crop Protection 22(1):39-44.

Delaquis PJ, Stanich K, Girard B, Mazza G (2002). Antimicrobial activity of individual and mixed fractions of dill, cilantro, coriander and eucalyptus essential oils. International Journal of Food Microbiology 74(1-2):101-109.

Dragomir F, Popa D (2008). Microbiology practice. Ed. Universitaria, Craiova.

Gîrd CE, Duțu LE, Popescu ML, Pavel M, Tudor I, Iordache AT, (2009). Theoretical and practical bases of analysis farmacognostice. vol. II, Ed. Curtea Veche, Bucharest.

Helander IM, Alakomi HL, Latva-Kala K, Mattila-Sandholm T, Pol I,Smid EJ, Gorris LGM, Von Wright A (1998). Characterization of the action of selected essential oil components on Gram-negative bacteria. Journal of Agricultural and Food Chemistry 46(9):3590-3595.

Hussain AI, Anwar F, Sherazi STH, Przybylski R (2008). Chemical composition, antioxidant and antimicrobial activities of basil (Ocimum basilicum) essential oils depends on seasonal variations. Food Chemistry 108(3):986-995.

Jiao J, Yu-Jie F, Yuan-Gang Z Meng L, Wei W, Lin Z, Ji L (2012). Enzyme-assisted microwave hydro-distillation essential oil from Fructus forsythia, chemical constituents, and its antimicrobial and antioxidant activities. Food Chemistry 134(1):235-243.

Jila A, Cheshmnaz KT, Mohsen M (2012). Microwave-assisted hydrodistillation of essential oils from Echinophora platyloba DC. Journal of Medicinal Plants Research 6(28):4475-4480.

Jirovetz L, Buchbauer G, Stoyanova AS, Georgiev EV, Damianova ST (2003). Composition, quality control, and antimicrobial activity of the essential oil of long-time stored dill (Anethum graveolens L.) seeds from Bulgaria. Journal of Agricultural and Food Chemistry 51(13):3854-3857. 
Kalemba D, Kunicka A (2003). Antibacterial and antifungal properties of essential oils. Current Medicinal Chemistry 10(10):813-829.

Lachowicz KJ, Jones GP, Briggs DR, Bienvenu FE, Wan J, Wilcock A, Coventry MJ (1998). The synergistic preservative effects of the essential oils of sweet basil (Ocimum basilicum L.) against acidtolerant food microflora. Letters in Applied Microbiology 26(3):209-214.

Lambert RJW, Skandamis PN, Coote PJA, Nychas GJ (2001). A study of the minimum inhibitory concentration and mode of action of oregano essential oil, thymol and carvacrol. Journal of Applied Microbiology 91(3):453-462.

Luu TD, Le NH, NgoDAT, JianZ, Raffaella M, NeilF (2013). Comparison of chemical composition, antioxidant and antimicrobial activity of lavender (Lavandula angustifolia L.) essential oils extracted by supercritical $\mathrm{CO}_{2}$, hexane and hydrodistillation. Food and Bioprocess Technology 6(12):34813489.

Lv F, Liang H, Yuan Q, Li C (2011). In vitro antimicrobial effects and mechanism of action of selected plant essential oil combinations against four food-related microorganisms. Food Research International $44(9): 3057-3064$.

Özcan M, Erkmen O (2001). Antimicrobial activity of the essential oils of Turkish plant spices. European Food Research and Technology 212:658-660.
Rauha JP, Remes S, Heinonen M, Hopia A, Kähkönen M, Kujala T, Pihlaja K, Vuorela H, Vuorela P (2000). Antimicrobial effects of Finnish plant extracts containing flavonoids and other phenolic compounds. International Journal of Food Microbiology 56(1):312.

Sandrine PI, Christian G, Giancarlo C, Farid C (2013). A comparison of essential oils obtained from lavandin via different extraction processes: Ultrasound, microwave, turbohydrodistillation, steam and hydrodistillation. Journal of Chromatography 1305:41-47.

Singh G, Marimuthu P (2006). Antioxidant and biocidal activities of Carum nigrum (seed) essential oil, oleoresin, and their selected components. Journal of Agriculture and Food Chemistry 54:174 181.

Sibel K, Sedef NE, Nural K, Serpil S, Gulum S, Beste B (2014). Microwave-assisted hydrodistillation of essential oil from rosemary. Journal of Food Science and Technology 51(6):1056-1065.

Solórzano-Santos F, Miranda-Novales MG (2012). Essential oils from aromatic herbs as antimicrobial agents. Current Opinion in Biotechnology 23(2):136-141.

Telci I, Bayram E, Yilmaz G, Avci B (2006). Variability in essential oil composition of Turkish basils (Ocimum basilicum L.). Biochemical Systematic Ecology 34:489-497.

Tongnuanchan P, Benjakul S (2014). Essential oils: extraction, bioactivities, and their uses for food preservation. Journal of Food Science 79(7):1231-1249. 